\title{
Research Article \\ Study on Vibration Characteristics and Human Riding Comfort of a Special Equipment Cab
}

\author{
Wu Ren ${ }^{D}{ }^{1}{ }^{1}$ Bo Peng, ${ }^{2}$ Jiefen Shen, ${ }^{1}$ Yang Li, $^{3}$ and Yi Yu $\mathbb{D}^{1}$ \\ ${ }^{1}$ School of Biomedical Engineering, Xinxiang Medical University, Xinxiang, Henan 453003, China \\ ${ }^{2}$ Hunan Special Equipment Inspection and Testing Research Institute Zhang Jiajie Branch, Zhangjiajie, Hunan 427000, China \\ ${ }^{3}$ College of Mechanical and Electrical Engineering, Central South University, Changsha, Hunan 410083, China
}

Correspondence should be addressed to Wu Ren; renwu88@126.com and Yi Yu; 203691831@qq.com

Received 19 July 2017; Accepted 11 December 2017; Published 7 February 2018

Academic Editor: Bruno Andò

Copyright ( ) $2018 \mathrm{Wu}$ Ren et al. This is an open access article distributed under the Creative Commons Attribution License, which permits unrestricted use, distribution, and reproduction in any medium, provided the original work is properly cited.

Special equipment drivers often suffered from vibration which threatened their physical and mental health. In order to study the riding comfort of a special equipment cab, a hammering experiment has been carried out on it by acceleration sensors. According to the test results, the natural frequency has been calculated which was compared with the result analysis by the finite element method. Next, the equipment operating condition test on a flat road was done. The vibration characteristics of the whole vehicle were obtained later. The results show that the cab vibration and the finite element results agree well, but the natural frequency of the cab is close to the vibration frequency of the human body. And this is not conducive to long-term operation of the drivers. In order to improve the human operational comfort, it is necessary to reduce its natural frequency during the cab structure design process. The research in this paper can provide help for the similar human-machine operation comfort study and product design.

\section{Introduction}

Due to the terrible working environment, some special engineering equipment dynamic characteristic and vibration laws are not researched as clear as other mechanics such as automobiles and trains. So, the study of the special equipment dynamic characteristic along with the vibration law can provide help for the product design and driver ride comfort of such equipment. Vehicle cab is an important part of manipulating and riding today. The human safety and comfort are directly related to vibration characteristics of the cab; thus, they have engineering and medical significance for drivers in a biomedical engineering field.

By far, the researchers of the special equipment cab vibration are mainly as follows: Caffaro et al. had made ergonomic research on a type of forklift vibration. Then, they analyzed the effect of the device active suspended cab on the human body vibration and did the study of the operators' comfort [1]. Aiming at improving operating conditions, Sun and Zhang had done the low-frequency vibration study of the bulldozer cab vibration; then, the structure design and improvement scheme of the equipment had been proposed [2]. Xu et al. had established a comprehensive model of a $\mathrm{cab}$ and an operator; then, the damping layout way had been researched [3]. Kang had built a 5-DOF human body model with a cab seat; then, the vibration control had been studied. Based on the results, the improved structure seat was carried out to enhance the human body ride comfort [4]. Tarabini et al. had proposed a high-performance vibration test for the human body in the operation of a special function device, which is of great significance to the study of the driver and seat safety [5]. Xiaoxiong had studied the human body vibration physiological parameters which are important for the human body and mechanical equipment ergonomics [6]. Yuezhen et al. had analyzed the vibration of human tactile feedback progress which was very helpful in the aerospace personnel comfort field [7]. Zhang et al. had established a 5 -DOF body sitting position model. Then, the vertical vibration characteristics of each part were obtained which provided dynamic design reference for the human-machine interface system [8]. Yingjie et al. had studied the ride comfort of the high-speed railway passenger system and had 
analyzed the influence of the vibration frequency on the human body's ride. Then, the comfort evaluation of a human machine can be obtained according to the body response [9]. Chao had studied a specialized engineering vehicle driver ride comfort and gave the research status and key technologies of it nowadays [10]. Zhiyan had studied the safety and comfort of a construction machinery cab in order to obtain the vehicle and personnel operating suitable working environment [11]. Minglong had made a vibration study on the cab of a certain type loader. Then, the structural design had been improved to reduce the cab vibration which gave the guidance to the comfort improvement of the human body [12]. Zhang et al. had established a mathematical model of a road vehicle and analyzed the vibration coupling effect [13]. Sim et al. had evaluated the hydropneumatic and semiactive cab suspension ride comfort of agricultural tractors and given a control algorithm for the suspension system [14]. Zhao et al. had built a hybrid model of seat-cab coupled system for a truck and did the cab suspensions test. Then, the parameters had been identified by the equipment [15]. Deboli et al. had done the whole body vibration measurement of horizontal and vertical transmissibility of an agricultural tractor seat. Finally, they had drawn the conclusion that the rolling and pitching effects can be reduced by using specific suspension systems along the horizontal and lateral directions [16]. Humphreys et al. have investigated the system dynamics which included the human operator and biodynamic feedthrough. Then, two methods of compensation for biodynamic feedthrough based on their models had been developed. The results showed that the operators perform better and prefer the vibration-compensating controllers over their non-vibration-compensating counterparts [17]. Sim et al. had proposed a hydropneumatic suspension applied with the semiactive control method. Then, the ride comfort has been predicted by using the vehicle model based on computer simulation in the end [18]. Talamonti et al. had described a new method called "mirage scenario" to support formative evaluation of driver alerting or warning displays for manual and automated driving. And the results showed that no collision avoidance maneuvers were performed; thereby, it reduced the risk of simulator sickness [19]. Mahmoodabadi et al. have introduced a novel combination of particle swarm optimization (PSO) and genetic algorithm (GA). The hybrid algorithm uses the operators such as mutation, traditional or classical crossover, multiple-crossover, and PSO formula. At the end, the algorithm had been used for the Pareto optimal design of a five-degree of freedom vehicle vibration model. The comparison of the obtained results demonstrated that it has a good result in the work [20]. Lepine et al. had proposed to use machine learning to identify shocks present in acceleration signals measured on road vehicles. Next, a machine learning algorithm has been trained to identify shocks buried within road vehicle vibration signals. The results showed that the machine learning algorithm was considerably more accurate and reliable in identifying shocks than the more common approaches [21]. Nariman-Zadeh et al. had proposed a new multiobjective uniform-diversity genetic algorithm (MUGA) called the $\varepsilon$-elimination algorithm. Then, it was used for Pareto optimization of a five-degree of freedom vehicle vibration model considering the five conflicting functions simultaneously. The results showed that the 5-objective optimization provided more choices for an optimal design of a vehicle vibration model [22]. Burdzik had presented a novel method for research on exposure to nonlinear vibration of passenger car suspension as a nonlinear dynamical system. The advantage of this method is possibilities of precise analysis of chosen frequency bands. Then, the influence of damping of shock absorber on exposure to vibration had been discussed [23]. Probabilistic metrics were used for a robust Pareto multiobjective optimum design of five-degree of freedom vehicle vibration model by Jamali et al. The robustness of the design obtained using such a probabilistic approach was shown and compared with that of the design obtained using deterministic approach in the end [24]. Auersch had performed a complex measuring campaign including the simultaneous measurement of vehicle, track, and soil vibrations during train runs at $16,25,40,63,80,100$, 125,140 , and $160 \mathrm{~km} / \mathrm{h}$ and analyzed the results then [25]. Lee et al. had introduced a damper that can reduce the amplitude of vibration in various frequency ranges. The electromagnetic damper can change its mode to respond to the vibration excitation at both low and high frequencies. The results were compared with those of a dynamic damper and indicated that the amplitude of vibration was reduced by $95.6 \%$ when the electromagnetic damper had been implemented on an H/Shaft [26]. Other researchers such as Wenku, Jinwu, Lin Xijun et al., and Lin also had made contribution to the cab vibration suppression for such equipment [27-30].

As can be seen in the studies of previous researchers, there are different studies in cab structure optimization, vibration characteristic, and human ride comfort of a special equipment. But so far, the study of special equipment has not yet formed unified laws such as vehicles and trains so the research of this special equipment such as the slag pot carrier vibration test is of great significance. In this paper, a special study of such metal slag transport equipment has been researched; then, the study of its cab vibration has been tested aiming at obtaining the vibration and working dynamic characteristics. This paper is organized as follows. In section 2, the modal theory is introduced and a finite element model of the cab has been established. In section 3 , a flat road test of the special equipment has been done. In section 4, a discussion between human body and the cab vibration is described. Finally, section 5 gives a conclusion. All of these give assistance to the cab structure optimization, vibration reduction, and human operating comfort research for engineers and doctors.

\section{Cab Modal Theory and Hammering Experiment}

The motion equation of the multi-degree-of-freedom system with proportional damping can be written as

$$
[M]\{\ddot{x}\}+[C]\{\dot{x}\}+[K]\{x\}=\{f(t)\} .
$$


In (1),

$$
[C]=\alpha[M]+\beta[K] .
$$

Here in (2), $\alpha$ and $\beta$ are the proportionality constants. $[C]$ is the damping matrix. So (2) has been called proportional damping equation. $[M]$ and $[K]$ are the mass and stiffness matrixes, where \{\} represents vector and [] represents matrix. By coordinate transformation, (3) can be obtained.

$$
\{x\}=\sum_{r=1}^{N} q_{r}\left\{\varphi_{r}\right\} .
$$

In (3), $\left\{\varphi_{r}\right\}$ is the $r$ th order mode which can be defined by $[M]\{\ddot{x}\}+[K]\{x\}=0$. By typing (3) into (1),

$$
\begin{gathered}
{[M]\left(\sum_{r=1}^{N} \ddot{q}_{r}\left\{\varphi_{r}\right\}\right)+[C]\left(\sum_{r=1}^{N} \dot{q}_{r}\left\{\varphi_{r}\right\}\right)} \\
+[K]\left(\sum_{r=1}^{N} q_{r}\left\{\varphi_{r}\right\}\right)=\{f(t)\} .
\end{gathered}
$$

Then, (4) is left multiplying $\left\{\varphi_{s}\right\}^{T}$, and if the modal vibration orthogonality has been taken into account, (5) and (6) can be written as

$$
\begin{aligned}
& \left\{\varphi_{s}\right\}^{T}[M]\left\{\varphi_{r}\right\}= \begin{cases}0, & r \neq s, \\
m_{s}, & r=s,\end{cases} \\
& \left\{\varphi_{s}\right\}^{T}[K]\left\{\varphi_{r}\right\}= \begin{cases}0, & r \neq s, \\
k_{s}, & r=s .\end{cases}
\end{aligned}
$$

Next,

$$
\begin{aligned}
\left\{\varphi_{s}\right\}^{T}[C]\left\{\varphi_{r}\right\} & =\alpha\left\{\varphi_{s}\right\}^{T}[M]\left\{\varphi_{r}\right\}+\beta\left\{\varphi_{s}\right\}^{T}[K]\left\{\varphi_{r}\right\} \\
& =\left\{\begin{array}{l}
0, \quad r \neq, \\
\alpha m_{s}+\beta k_{s}=c_{s}, \quad r=s .
\end{array}\right.
\end{aligned}
$$

In (7), $m_{s}, k_{s}$, and $c_{s}$ are respective of the $s$ th order modal mass, stiffness, and modal damping coefficients. And furthermore, (8) can be gotten by

$$
m_{s} \ddot{q}_{s}+c_{s} \dot{q}_{s}+k_{s} q_{s}=\left\{\varphi_{s}\right\}^{T}\{f(t)\} .
$$

In (8), $q_{s}$ is the sth order modal coordinate. Let $\{f(t)\}=$ $\{F\} e^{j \omega t}$ then $q_{s}=Q_{s} e^{j \omega t}$. By substituting it into (8),

$$
\begin{aligned}
\left(-\omega^{2} m_{s}+j \omega c_{s}+k_{s}\right) Q_{s} e^{j \omega t} & =\left\{\varphi_{s}\right\}^{T}\{F\} e^{j \omega t}, \\
Q_{s} & =\frac{\left\{\varphi_{s}\right\}^{T}\{F\}}{-\omega^{2} m_{s}+j \omega c_{s}+k_{s}} .
\end{aligned}
$$

In (9) and (10), $Q_{s}$ is a modal coordinate vector with amplitude and phase which can be seen as a response of a single-degree-of-freedom system with mass, stiffness, and damping, respectively, $m_{s}, k_{s}, c_{s}$ under the action of modal force $P_{s}=\left\{\varphi_{s}\right\}^{T}\{F\} . Q_{s}$ is the phase with respect to the excitation force. So the displacement response is obtained according to (3) as seen in (11) and (12).

$$
\begin{aligned}
\{x\} & =\left\{\begin{array}{c}
X_{1} \\
X_{2} \\
\vdots \\
X_{N}
\end{array}\right\} e^{j \omega t}=\sum_{r=1}^{N} q_{r}\left\{\varphi_{r}\right\}=\sum_{r=1}^{N} Q_{r}\left\{\varphi_{r}\right\} e^{j \omega t}, \\
\{X\} & =\left\{\begin{array}{c}
X_{1} \\
X_{2} \\
\vdots \\
X_{N}
\end{array}\right\}=\sum_{r=1}^{N} Q_{r}\left\{\varphi_{r}\right\}=\sum_{r=1}^{N} \frac{\left\{\varphi_{r}\right\}^{T}\{F\}\left\{\varphi_{r}\right\}}{-\omega^{2} m_{r}+j \omega c_{r}+k_{r}} \\
& =\sum_{r=1}^{N} \frac{\left\{\varphi_{r}\right\}\left\{\varphi_{r}\right\}^{T}}{-\omega^{2} m_{r}+j \omega c_{r}+k_{r}}\{F\} .
\end{aligned}
$$

Equation (12) is a modal shape in which the proportional viscous damping system has been considered which can be converted into

$$
\{X\}=\sum_{r=1}^{N} \frac{\left\{\varphi_{r}\right\}\left\{\varphi_{r}\right\}^{T}\{F\}}{k_{r}\left[1-\left(\omega / \Omega_{r}\right)^{2}+j 2 \zeta_{r}\left(\omega / \Omega_{r}\right)\right]} .
$$

In (13), $\Omega_{r}=\sqrt{k_{r} / m_{r}}$ and $\left\{\varphi_{r}\right\}$ are the eigenvectors of no damping vibration system which represent the vibration amplitude ratio of each particle at the time of natural frequency $\Omega_{r}$. According to the multifreedom modal theory and based on the test equipment, the hammering test experiment has been carried out in the following process.

The test object is a metal slag transfer vehicle. If the diver operates it during a long time in the cab, he will have dizziness, nausea, and tinnitus problems. In order to improve the human-computer interaction and operational comfort, the special vibration test will include two aspects: (1) cab interior hammering test which aims at getting its vibration characteristics. (2) normal working condition on the flat road: the purpose of the test is to determine whether there is resonance between the vehicle cab vibration and the body with the human physical parameters. Furthermore, it can provide help for the study of human comfort when operating the vehicle. The test velocity is $25 \mathrm{~km} / \mathrm{H}$ on the 500 -meter-long flat road.

Dynamic data acquisition instrument called Dewesoft has been adopted as shown in Figure 1. It has 16 input and output channels, 6 acceleration channels, and 2 CAN modules. The collected pressure, displacement, strain, and data can be gotten and postprocessed by it. The cab is fixed on a steel plate by means of a shock absorber. Then, the ICP acceleration sensors are arranged as shown in Figures 1 and 2. Besides the test, data is collected by using DS-NET signal collecting and processing instrument.

By hammering the around corners of the cab, the left rear corner, and the right rake angle, the 3rd accelerator signal time curve under the deck of the cab is shown in Figure 3. 


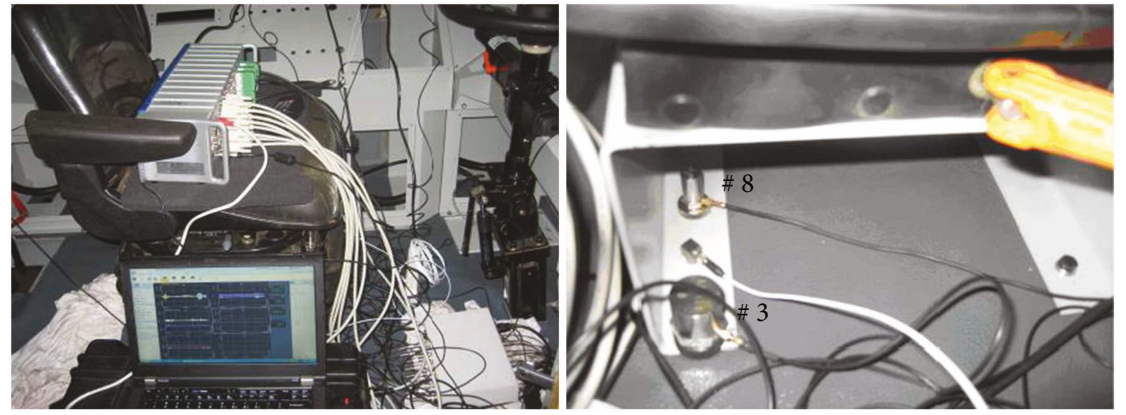

FIGURE 1: The measure equipment and number 3 and number 8 sensor arrangement.

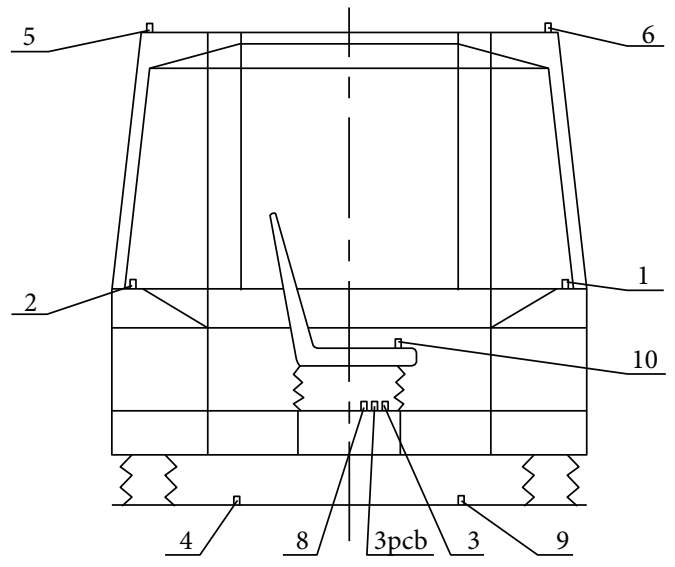

Figure 2: Arrangement of the sensors in the test.

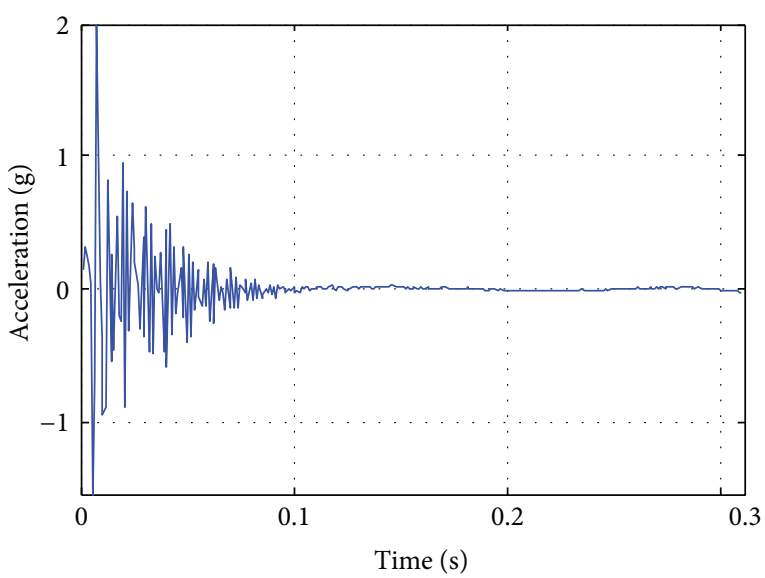

Figure 3: The 3rd sensor acceleration time domain signal of the left rear hammering under the driver's seat.

By the frequency domain analysis of the cab system, the first two order natural frequencies can be obtained: $7.8 \mathrm{~Hz}$ and $12.5 \mathrm{~Hz}$. And the damping ratio is about 0.213 . The vertical hammer analysis of the cab's right front corner is shown in Figure 4.

By the frequency domain analysis of the cab system, the first two order natural frequencies can be obtained: $7.3 \mathrm{~Hz}$ and $11.7 \mathrm{~Hz}$. And the damping ratio is about 0.222 .

According to the left and right rear corner test results, the obtained frequencies of the cab below $20 \mathrm{~Hz}$ are $7.1 \mathrm{~Hz}$,

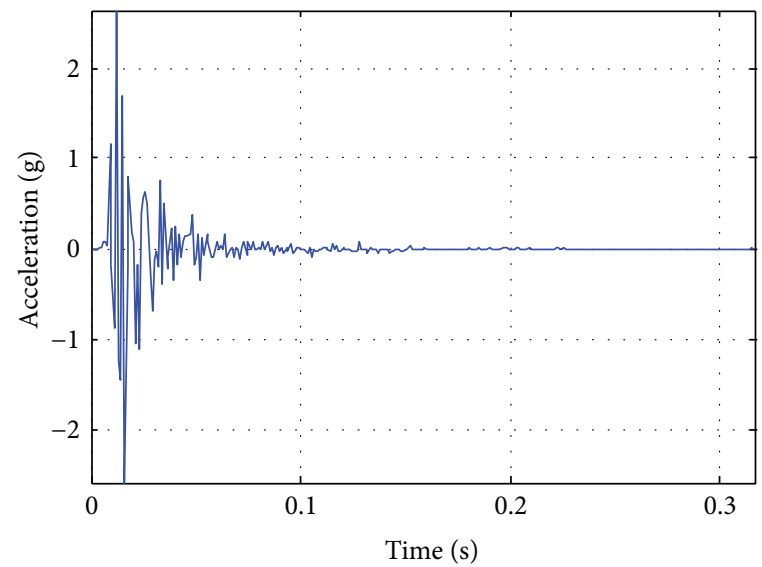

FIgURE 4: The 3rd sensor acceleration time domain signal of the right front hammering under the driver's seat.

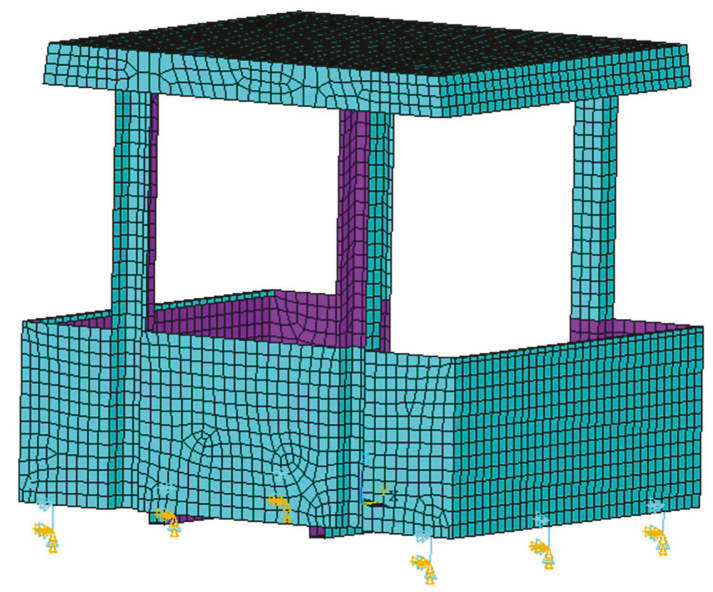

FIgURE 5: Natural frequency solving finite element.

$7.8 \mathrm{~Hz}$, and $12 \mathrm{~Hz}$. In order to verify the results, a finite element model of the cab has been established as shown in Figure 5 . Then, the vibration characteristics and the corresponding vibration modes have been calculated. The cab used Shell63 unit in the finite model. The shock absorber between the cab and the frame used combine 14 units. Then, the first four order modes have been calculated then. The natural frequency values are $6.80 \mathrm{~Hz}, 7.95 \mathrm{~Hz}$, $12.02 \mathrm{~Hz}$, and $12.04 \mathrm{~Hz}$ which are in good agreement with the test results. 


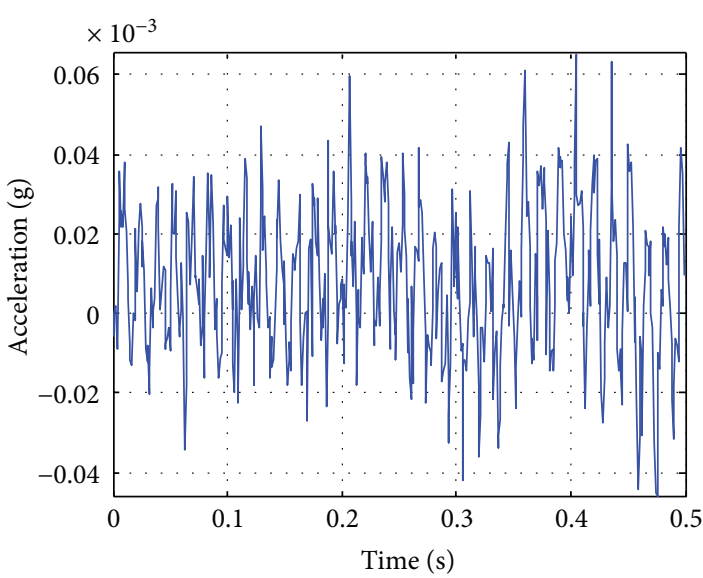

(a) The 4th sensor acceleration of the frame plate

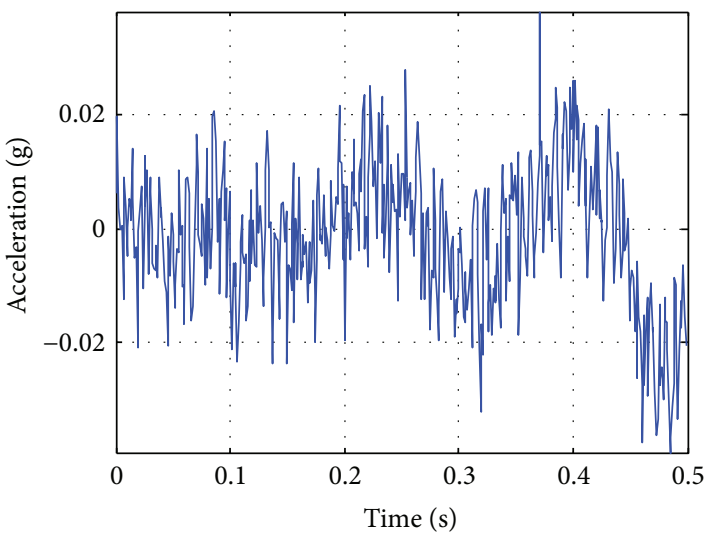

(c) The 8th sensor acceleration under the cab seat

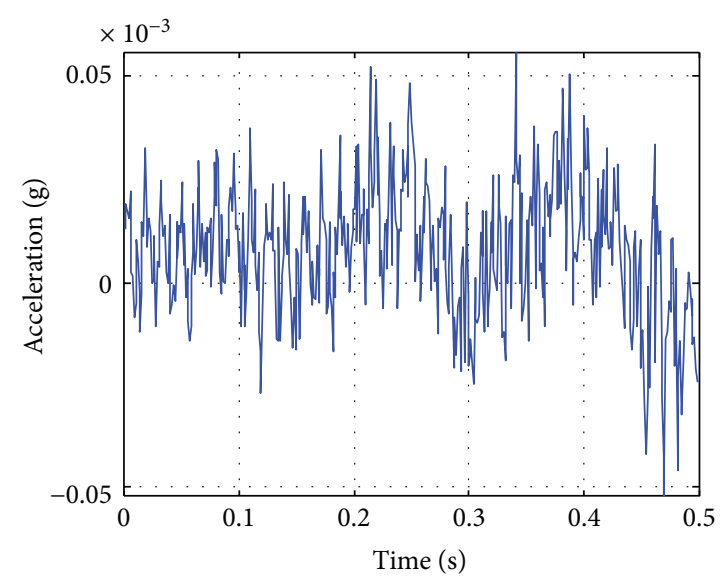

(b) The 9th sensor acceleration of the frame plate

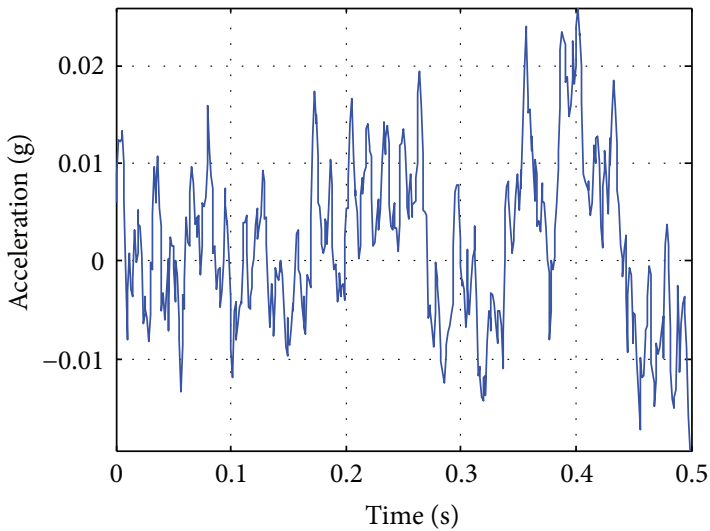

(d) The 2nd sensor acceleration of the frontier dashboard

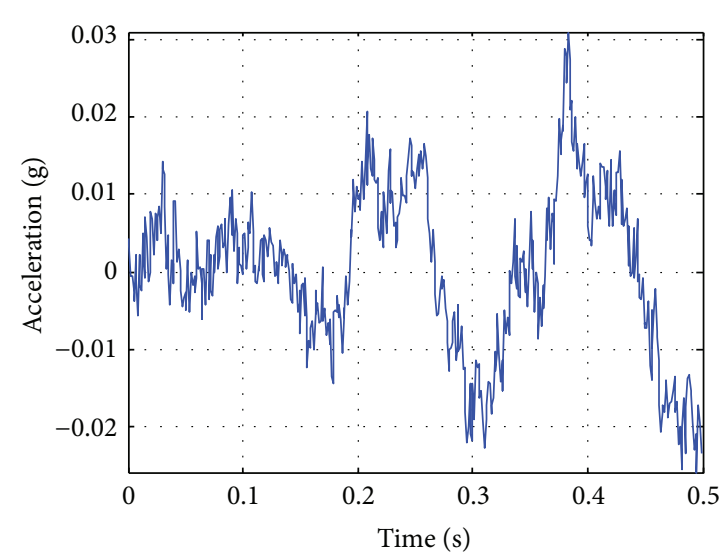

(e) The 1st sensor acceleration of the rear dashboard

Figure 6: Acceleration time-domain tested signal of the flat road condition.

\section{Flat Road Motion Test}

The equipment usually works on the flat road so it is of great importance to do the flat road work condition test. According to the measuring point arrangement from the test field, the acceleration signal data within $0.5 \mathrm{~s}$ has been collected. The time domain data of the frame steel plate (acceleration sensors 4 and 9), under the seat (acceleration sensor 8), and the instrument panel (acceleration sensors 1 and 2) are shown in Figure 6. Besides the acceleration sensor 4, 9, and 8 frequencies, domain curves are shown in Figure 7.

By analyzing the frame plate (acceleration sensors 4 and 9) and under the seat (acceleration sensor 8) acceleration spectrum, it can be calculated that each spectrum has a different degree of peak at the frequency of $4.8 \mathrm{~Hz}$. This indicates that there exists a natural frequency near the $4.8 \mathrm{~Hz}$ of the vehicle. This natural frequency along with the first three order natural frequencies of the cab and the natural 


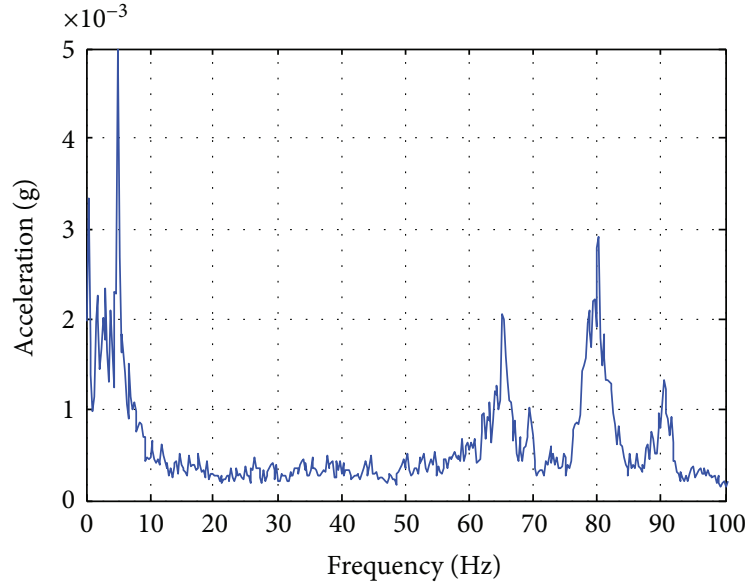

(a) The 4th sensor acceleration spectrum of the frame plate

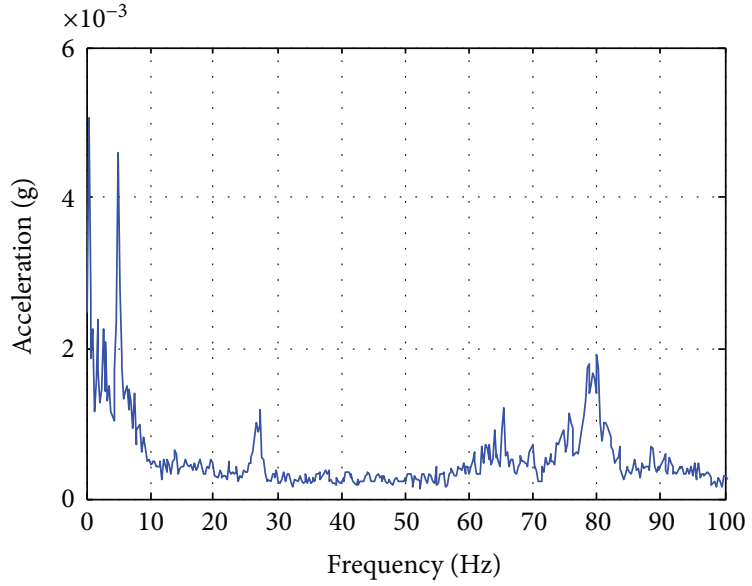

(b) The 9th sensor acceleration spectrum of the frame plate

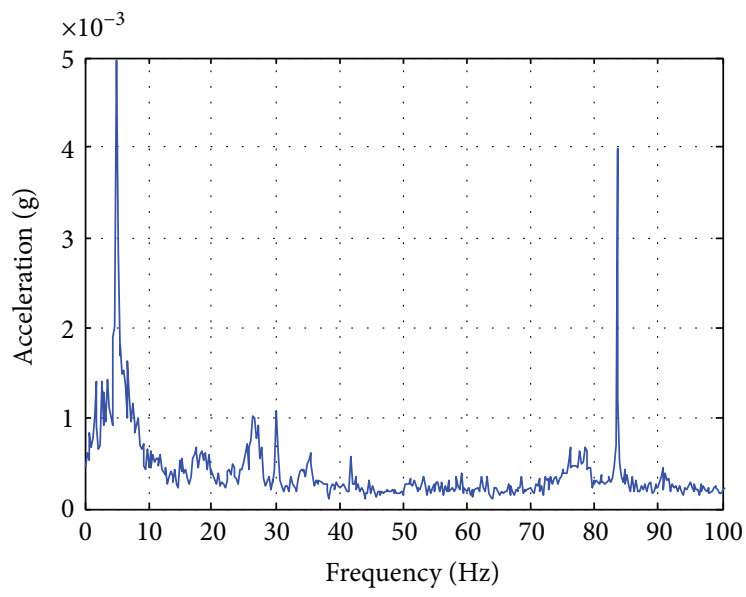

(c) The 8th sensor acceleration spectrum under the cab seat

Figure 7: Number 4, 9, and 8 sensor acceleration spectrum curve.

frequency vibrations of the driver's body part of the organism will resonate if they are similar. The occurrence of resonance will cause different physiological discomforts of the operators.

\section{Human Vibration Parameter Comparison and Result Discussion}

According to the existing research, the natural frequency of a human-standing body is about $7.5 \mathrm{~Hz}$, and the frequency of a sitting posture in the cab is generally $4-6 \mathrm{~Hz}$. The natural frequency of the main body parts is shown in Table 1 .

It can be seen from Table 1 that the natural frequencies of the human spine and head are relatively large in all parts. This is because most of these two parts are composed of rigid bodies, and the degree of flexibility is relatively small. The frequency of the thoracic cavity and heart is about $5 \mathrm{~Hz}$, relatively small, because both parts are muscular tissues with a high degree of flexibility. The natural frequencies of other parts, such as the pelvic cavity and the abdomen, are in the middle position.

Thus, the resonance is likely to occur among the cab, the whole vehicle, and the operator. If the special equipment driver is in the vibration environment for a long-term
TABLE 1: The main part of the human body natural frequency.

\begin{tabular}{lc}
\hline Body part & Natural frequency $(\mathrm{Hz})$ \\
\hline The whole body & 7.5 \\
Body torso & $7-13$ \\
Head & $8-12$ \\
Thoracic cavity & $4-6$ \\
Heart & 5 \\
Abdominal cavity & $6-9$ \\
Spine & $10-12$ \\
Pelvic & 6
\end{tabular}

without control, the motion, urinary, digestive, nervous, and cardiovascular system diseases will lead to physiological health disease either. So in order to protect the driver's physical and mental health, the vibration of the equipment must be controlled in a reasonable range. It is close to the natural frequency of the chest and heart. Therefore, in order to avoid the two parts being affected by resonance, it is necessary to be close to the seat when driving. It can form a system with the seat, so as to improve the natural frequency of the whole vehicle and avoid the self-resonance area. The important 
parts of the human body vibration frequency are generally located in about $3 \mathrm{~Hz}-17 \mathrm{~Hz}$. According to the International Standard ISO 2631 in the vertical vibration of the human body, the sensitive range is located in $6 \mathrm{~Hz}-8 \mathrm{~Hz}$. In this range, the EMG and EEG energies will have a substantial increase due to the vibration. When the body vibration frequency reaches $10 \mathrm{~Hz}-20 \mathrm{~Hz}$, the skeletal muscle will have a tight contraction. Then, it will suppress the tendon reflex. According to the test of this special equipment, there is a natural frequency near $4.8 \mathrm{~Hz}$ of the machine. The first three order frequencies of the vehicle cab are $7.1 \mathrm{~Hz}, 7.8 \mathrm{~Hz}$, and $12 \mathrm{~Hz}$ which are close to the equipment normal work condition frequency and the driver's physical parameters. The natural frequencies of the head and spine are closer to them. Therefore, head fixtures can be added in the cab seat, and try to put the head in the fixed slot as far as possible, and the back of the body should be close to the seat either. It can effectively avoid the resonance frequency range by making a whole system with the seat. Finally, the drivers' discomfort can be decreased to the maximum degree.

\section{Conclusion}

From the "people-oriented" concept, in order to reduce the operator's long-term operation of the special equipment, which may cause physical and mental health damage, a special equipment cab system hammer test and the whole vehicle flat road motion test have been done. The conclusion can be drawn as follows:

(1) By the hammering test analysis of the equipment cab, the first 3 order natural frequencies of the system are about $7 \mathrm{~Hz}, 7.8 \mathrm{~Hz}$, and $12 \mathrm{~Hz}$. Besides, the damping ratio is about $21 \%$, which is close to the vibration sensitive range of the human body.

(2) The cab shock absorber has a part of the vibration suppression effect of the flat road random excitation which improves the driver's operating comfort to some certain extent. The natural frequency of the cab system is higher than that of the whole vehicle. But the damping pad usually works at a low frequency near the natural frequency of the whole vehicle which cannot play a good damping effect for a long time. At the same time, the driver and the seat are in direct contact so the human body is in the most uncomfortable frequency vibration range.

(3) In order to improve the comfort of the driver, it is necessary to reduce the natural frequency of the cab structure in the design process. Furthermore, when the cab frequency has been reduced, the shock absorber can work efficiently which is of help for the working safety of the machine also.

(4) The lower the whole vehicle and the cab natural frequency the more conducive for the operators to avoid the body vibration uncomfortable area. So the equipment full load capacity and cab structure design should be considered at the same time.

\section{Conflicts of Interest}

The authors declare that they have no conflicts of interest.

\section{Acknowledgments}

This work was supported by "Human machine dynamic characteristics of multi degree of freedom rehabilitation displacement device" (172102310542), "Multi-DOF Rehabilitation patient transfer device dynamics characteristic and human-machine safety comfort research"(505140), "Human comfort study by elevator transportation based on multi-body dynamics" (no. 2015KYJH33), the Natural Science Foundation of Henan province (2014GGJS-096 and 152102310357), Abnormal shear stress mediated expression of PCSK9 in atherosclerotic plaque cells (152102210339), and Effect of mechanical factors on protein expression in atherosclerotic plaque cells (15a180056).

\section{References}

[1] F. Caffaro, M. M. Cremasco, C. Preti, and E. Cavallo, "Ergonomic analysis of the effects of a telehandler's active suspended cab on whole body vibration level and operator comfort," International Journal of Industrial Ergonomics, vol. 53, no. 5, pp. 19-26, 2016.

[2] X. Sun and J. Zhang, "Performance of earth-moving machinery cab with hydraulic mounts in low frequency," Journal of Vibration and Control, vol. 20, no. 5, pp. 724-735, 2014.

[3] P. Xu, B. Bernardo, and K. Tan, "Optimal mounting design for cab vibration isolation," International Journal of Vehicle Design, vol. 57, no. 2/3, pp. 292-304, 2011.

[4] J. S. Kang, "Ride quality analysis using seated human vibration modeling," Journal of the Korean Society for Railway, vol. 18, no. 3, pp. 194-202, 2015.

[5] M. Tarabini, B. Saggin, D. Scaccabarozzi, and G. Moschioni, "The potential of micro-electro-mechanical accelerometers in human vibration measurements," Journal of Sound and Vibration, vol. 331, no. 2, pp. 487-499, 2012.

[6] J. Xiaoxiong, "Study on the influence of vibration on human physiological parameters," Ergonomics, vol. 3, no. 2, pp. 1822, 1997.

[7] H. Yuezhen, Z. Kanghan, S. Jianfeng, and J. Linhong, "Advancement of research on vibrotactile feedback of human body," Space Medicine \& Medical Engineering, vol. 28, no. 4, pp. 298-302, 2015.

[8] E. Zhang, L. Z. Hua, and S. Xiaochun, "Simulation of human vibration characteristics based on 9-DOF riding dynamics model," Journal of Traffic and Transportation Engineering, vol. 10, no. 4, pp. 58-64, 2010.

[9] W. Yingjie, S. Jin, L. Xuyou, and X. Ye, "Dynamic responses of high speed railway human body-vehicle system and comfort evaluation," Journal of Central South University (Science and Technology)., vol. 44, no. 7, pp. 3046-3052, 2013.

[10] C. Chao, "Research status and key technologies for seating comfort of engineering vehicles," Construction Machinery, vol. 56, no. 1, pp. 71-75, 2012.

[11] J. Zhiyan, Research on Safety and Comfort Design Construction Machinery Cab, Nanjing University of Aeronautics and Astronautics, Nanjing, China, 2014. 
[12] D. Minglong, "Analysis and Research on Vibration Absorption of Construction Machinery Cab," Shandong University, Jinan, China, 2011.

[13] J. Zhang, P. Guo, J. Lin, and K. Wang, "A mathematical model for coupled vibration system of road vehicle and coupling effect analysis," Applied Mathematical Modelling, vol. 40, no. 2, pp. 1199-1217, 2016.

[14] K. Sim, H. Lee, J. W. Yoon, C. Choi, and S. H. Hwang, "Effectiveness evaluation of hydro-pneumatic and semi-active cab suspension for the improvement of ride comfort of agricultural tractors," Journal of Terramechanics, vol. 28, no. 2, pp. 23-32, 2017.

[15] L. L. Zhao, C. C. Zhou, and Y. W. Yu, "Hybrid modeling of seat-cab coupled system for truck," International Journal of Automo 'tive Technology, vol. 17, no. 5, pp. 769-776, 2016.

[16] R. Deboli, A. Calvo, and C. Preti, "Whole-body vibration: measurement of horizontal and vertical transmissibility of an agricultural tractor seat," International Journal of Industrial Ergonomics, vol. 58, no. 3, pp. 69-78, 2017.

[17] H. C. Humphreys, W. J. Book, and K. M. Feigh, "Development of controller-based compensation for biodynamic feedthrough in a backhoe," Proceedings of the Institution of Mechanical Engineers, Part I: Journal of Systems and Control Engineering., vol. 228, no. 2, pp. 107-120, 2014.

[18] K. Sim, H. Lee, J. W. Yoon, C. Choi, and S. H. Hwang, "Effectiveness evaluation of hydro-pneumatic and semi-active cab suspension for the improvement of ride comfort of agricultural tractors," Journal of Terramechanics, vol. 69, no. 2, pp. 23-32, 2017.

[19] W. Talamonti, L. Tijerina, M. Blommer, R. Swaminathan, R. Curry, and R. D. Ellis, "Mirage events \& driver haptic steering alerts in a motion-base driving simulator: a method for selecting an optimal HMI," Applied Ergonomics, vol. 65, no. 11, pp. 90-104, 2017.

[20] M. J. Mahmoodabadi, A. A. Safaie, A. Bagheri, and N. Nariman-zadeh, "A novel combination of particle swarm optimization and genetic algorithm for Pareto optimal design of a five-degree of freedom vehicle vibration model," Applied Soft Computing, vol. 13, no. 5, pp. 2577-2591, 2013.

[21] J. Lepine, V. Rouillard, and M. Sek, "On the use of machine learning to detect shocks in road vehicle vibration signals," Packaging Technology and Science, vol. 30, no. 8, pp. 387398, 2017

[22] N. Nariman-Zadeh, M. Salehpour, A. Jamali, and E. Haghgoo, "Pareto optimization of a five-degree of freedom vehicle vibration model using a multi-objective uniform-diversity genetic algorithm (MUGA)," Engineering Applications of Artificial Intelligence, vol. 23, no. 4, pp. 543-551, 2010.

[23] R. Burdzik, "Novel method for research on exposure to nonlinear vibration transferred by suspension of vehicle," International Journal of Non-Linear Mechanics, vol. 91, no. 5, pp. 170-180, 2017.

[24] A. Jamali, M. Salehpour, and N. Nariman-zadeh, "Robust Pareto active suspension design for vehicle vibration model with probabilistic uncertain parameters," Multibody System Dynamics, vol. 30, no. 3, pp. 265-285, 2013.

[25] L. Auersch, "Simultaneous measurements of the vehicle, track, and soil vibrations at a surface, bridge, and tunnel railway line," Shock and Vibration, vol. 2017, Article ID 1959286, 18 pages, 2017.
[26] K. H. Lee, J. H. Bak, J. L. Park, and C. H. Lee, "Vibration reduction of H/Shaft using an electromagnetic damper with mode change," International Journal of Automotive Technology, vol. 18, no. 2, pp. 255-261, 2017.

[27] S. Wenku, "Dynamic characteristics matching of hydraulic suspension based on elastic cab," Journal of Vibration, Measurement and Diagnosis, vol. 34, no. 3, pp. 409-413, 2014.

[28] W. Jinwu, "Design of driving adaptability of combine harvester cab based on ergonomics," Journal of Northeast Agricultural University, vol. 45, no. 3, pp. 97-103, 2014.

[29] L. Xijun, Z. Xiqiang, and Z. Suxia, "Vibration analysis and comfortableness evaluation of a human-vehicle-bridge coupled system," Mechanical Science and Technology, vol. 33, no. 9, pp. 1387-1392, 2014.

[30] Z. Lin, "The NVH phenomena analysis in corn harvesterbased on vibration dose and a-meter-weight noise," Journal of Agricultural Mechanization Research, vol. 37, no. 12, pp. 245-250, 2015. 


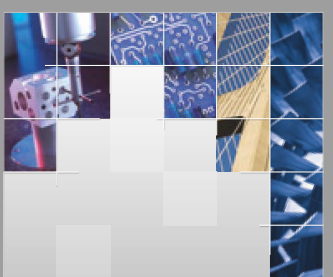

\section{Enfincering}
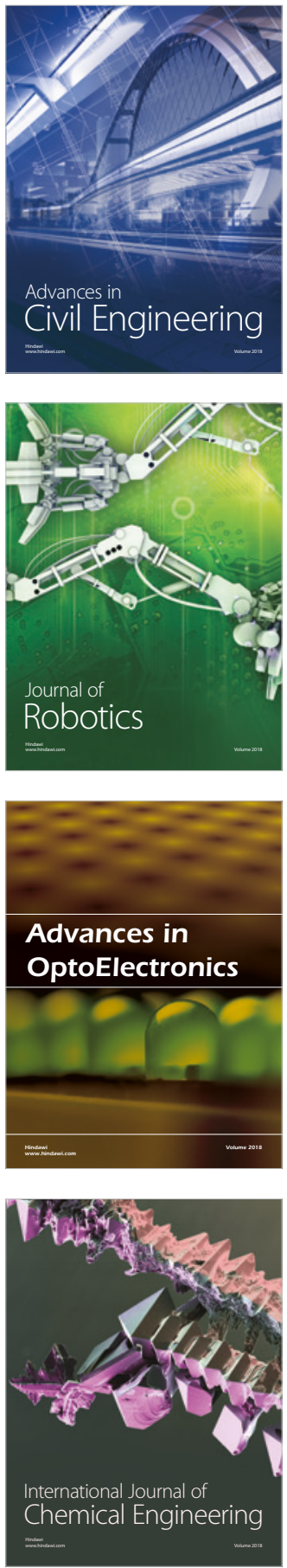

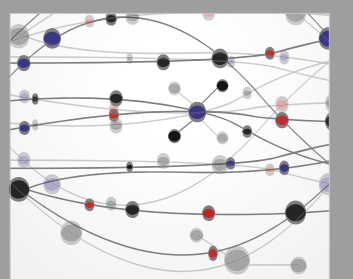

\section{Rotating \\ Machinery}

The Scientific World Journal

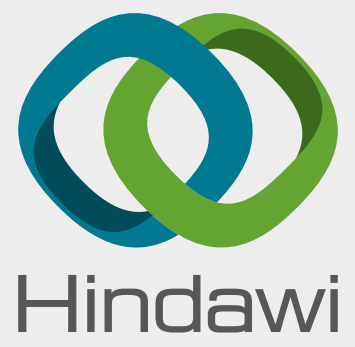

Submit your manuscripts at

www.hindawi.com
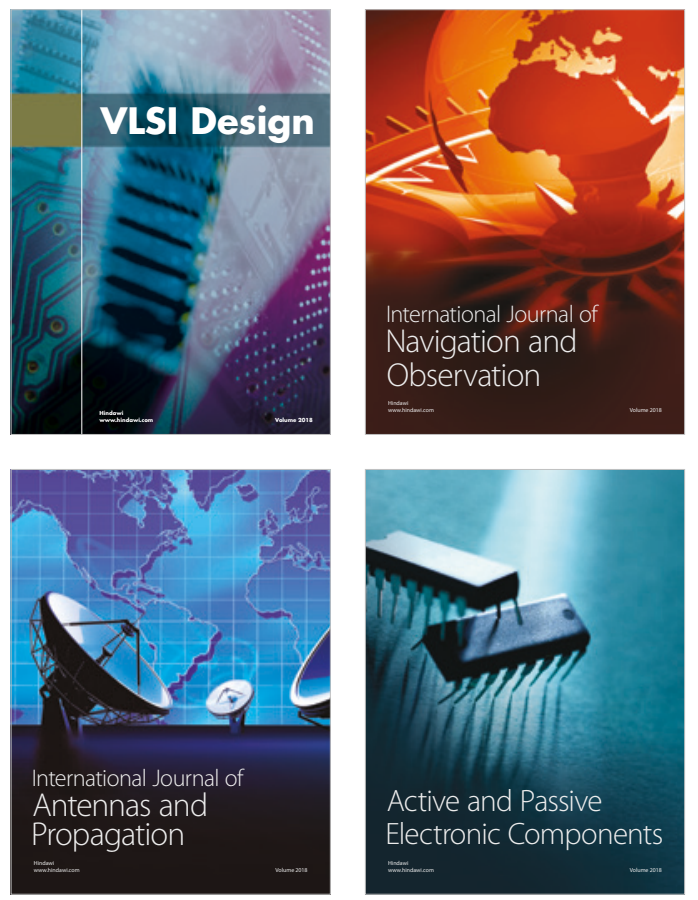
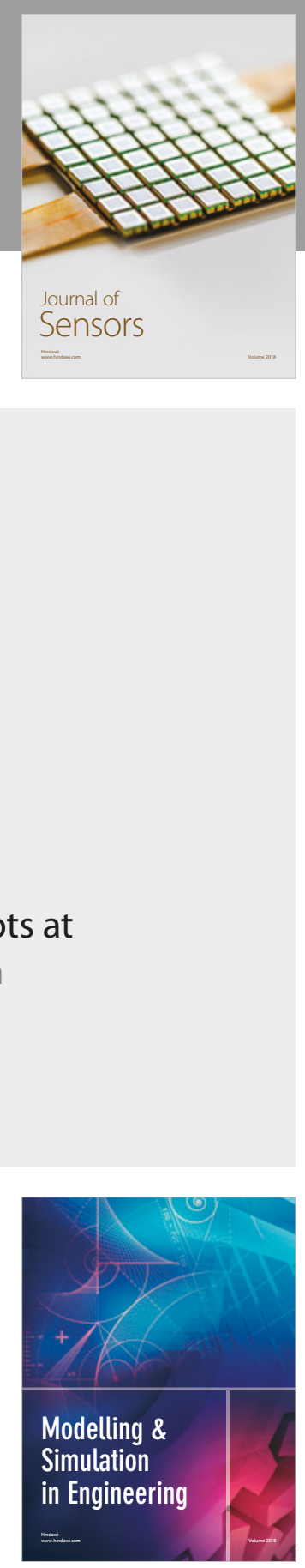

\section{Advances \\ Multimedia}
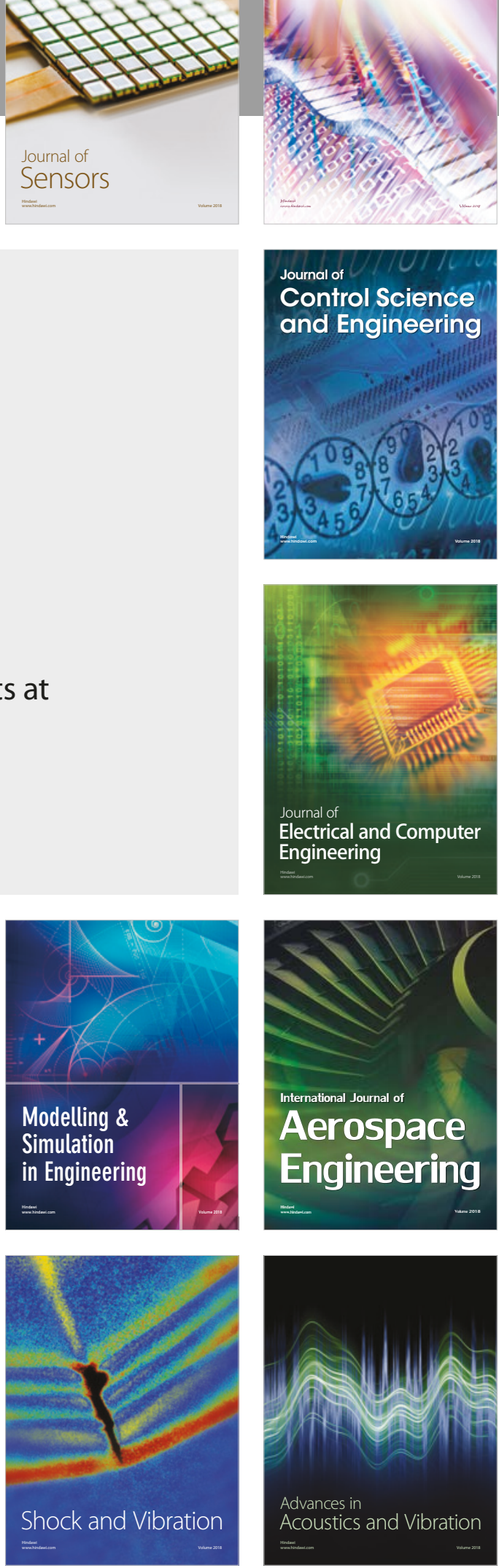